\title{
ANALYSIS OF DIFFERENT LOADS AFFECTING THE URBAN RALLWAY TUNNEL SYSTEMS OF CAIRO METRO UNDERNEATH THE RIVER NILE
}

Hamdy.H.A.Abd-el.rahim ${ }^{1}$, Mahmoud Enieb ${ }^{2}$, Ahmed Abdelmoamen Khalil ${ }^{3}$, Abdou SH.Ahmed ${ }^{4}$

${ }_{1,2,4}$ Department of Civil Engineering, Assiut University, Assiut, 71516, Egypt

${ }^{3}$ Department of Civil Engineering, Shoubra faculty of Engineering, Benha University Benha, 11629, Egypt

Received 11 May 2014; accepted 1 October 2014

\begin{abstract}
The study objective of this paper is analysis of different loads affecting the urban railway tunnel systems to determine the optimum tunnel system (single tunnel or twin tunnel). A case study is The Greater Cairo metro line No. 4, which passes under the River Nile in Egypt land. Analysis of settlement and stresses was carried out using three different finite element programs (Ansys, Plaxis and Rocscience Phase). We obtained optimum dimension of the model for the different tunnel systems. Also, vertical and horizontal bed River Nile settlements were computed for single and twin tunnel by the above mentioned programs. The comparison between the two systems in terms of bending moments and settlement is presented. Also, the procedures of construction of the twin tunnel underneath the River Nile were discussed. Moreover, the effect of the train loads on the settlement profile and the horizontal displacement of bed River Nile were evaluated for single and twin tunnel systems. Based on the calculated result, higher stresses in bottom tunnel (twin tunnel system) increased by $100 \%$ about stresses in a single tunnel. When trains pass through the tunnel, stresses decrease about $10 \%$ for single tunnel and about $5 \%$ for twin tunnels.
\end{abstract}

Keywords: railway, tunnel systems, stresses, finite element analysis, deformations.

\section{Introduction}

The River Nile which runs through Cairo gives it an attractive and gorgeous view. The urban center is crowded with people, so tunnels and bridges have been constructed to transport large numbers of people across the river. Bridges cause traffic congestion along the roads going to the bridge. Therefore, the optimal solution for the conveyance of the people is tunnels. Especially if the tunnels were extended and connected as subway network under the city.
The Great Cairo Region is a premier city in Egypt. It is rich in history and boasts of a large number of historic structures. It is a large city in the Africa and the Middle East Region. Phase No.1 of line No. 4 will extend from El-Malek El-Saleh station on line No. 1 to Remaya square station as shown in Fig. 1. It will meet the route of line No. 2 in Giza station. The study area for Greater Cairo Metro Line No. 4 starts from Station No. 1 (El-Malek El-Saleh) and extend up to Station No. 5 (El Mesaha Station).

${ }^{3}$ Corresponding author: ahmed.khalil@feng.bu.edu.eg 
Moller (2006) studied the internal forces in tunnel lining and displacement of soil and found that tunnel design needs an honest idea of surface settlements and lining internal forces. Garner and Coffman (2012) found that the design of the tunnel depends on the induced settlement in the tunnel. Therefore, they proposed method giving acceptable ground surface settlement profile to generate a tunnel system configuration, as well as the proposed characterization method can be used to help designers to eliminate potential configurations that would cause excessive surface settlements. Chen et al. (2012) concluded that a good estimation of surface settlement is very important to the construction of tunnels in very crowded cities because failure of neigh boring structures due to extra surface settlement above the tunnels, they examined the interaction of multi-tube tunnels on ground surface settlement and the methods of prediction for the transverse ground surface settlement profile. Wang et al. (2012) found that for shallow tunnels constructed in clay soil, a surface settlement above tunnels depend on the creep of soil, they concluded that behaviour of clay creep is very important for long term settlement above the tunnel. Mazek and Almannaei (2013) used finite element analysis to determine the model dimension of cross section for line No. 3 at Cairo metro and he found that minimum width equal to ten times of the diameter of the tunnel. Migliazza et al. (2009) computed vertical settlement of ground surface during excavation and using empirical method and finite element analysis, they found numerical data similar to experimental data. Wang and $\mathrm{Su}$ (2011) compared the ground settlement by using the Ansys program and by using excavation program data, they found that it is possible to use Ansys program compared with the original data in excavation program. Mazek (2011) forecasting performance of ELAzhar tunnel systems, he used finite element model to analyse twin tunnel construction, and concluded that the computed surface settlement different from measurement data in the field by $10 \%$. Chehade and Shahrour (2008) concluded that construction of tunnels causes movement of soil and staining action in lining of the tunnel, also the procedure of construction impact on soil settlement and lining forces.

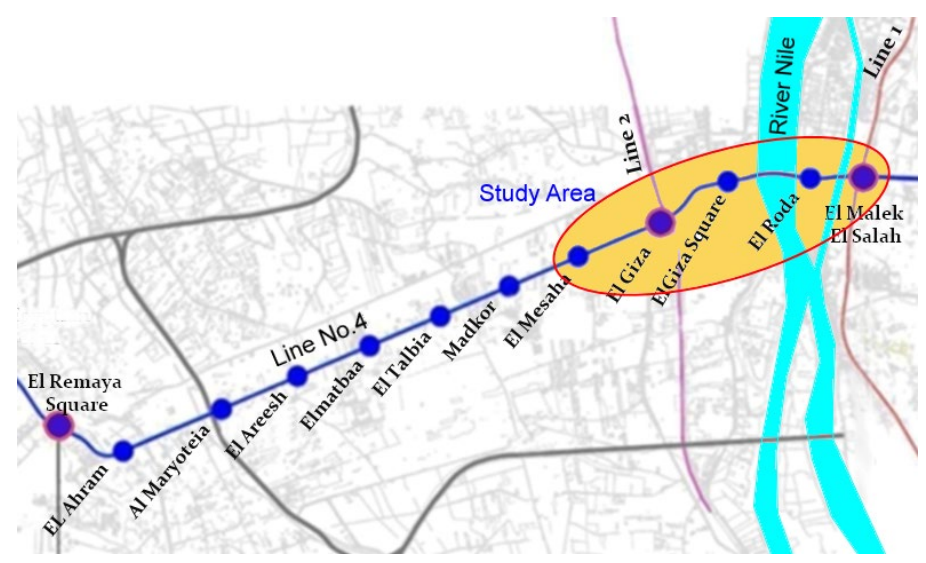

Fig. 1.

General Layout of Greater Cairo Metro Line No. 4 (Phase No. 1)

Source: JICA Project document (2010) 


\section{Train Axle Load}

Axle load of trains of Cairo metro line No. 4 equals to 16 tons as shown in Fig. 2 (Khalil, 2002; Nejati et al., 2012).

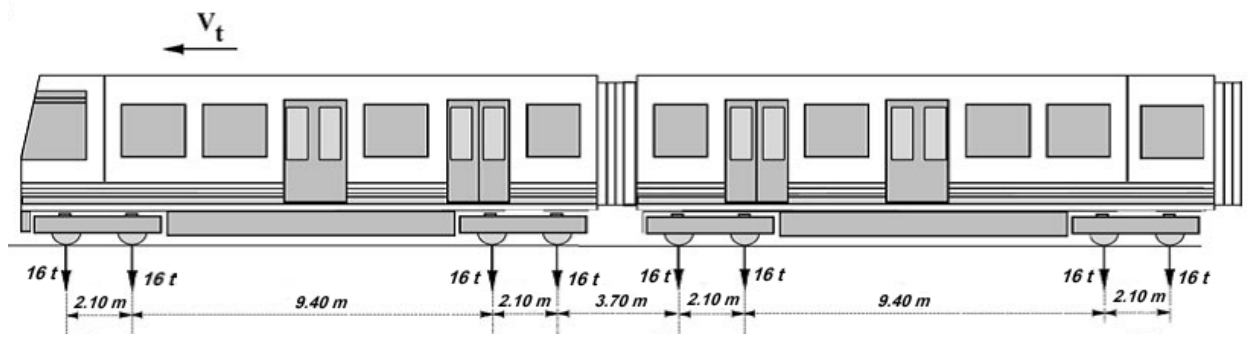

Fig. 2.

Train Axle Load for Cairo Line No. 4

\section{Geological Profile}

Fig. 3 shows the geological section based on the obtained data from the National Authority of Tunnels (NAT) in Cairo. In this figure, there are three main soil layers namely, very dense sand, Silty-sand and SiltyClay. The physical and mechanical properties of these layers are documented in Table 1 and Table 2. Most of the tunnel is planned to run through the very dense sand layer. The physical and mechanical properties of concrete segment were documented in Table 3. Site investigations along line No. 4 alignment indicate that the soil profile cross section under River Nile as shown in Fig. 4.

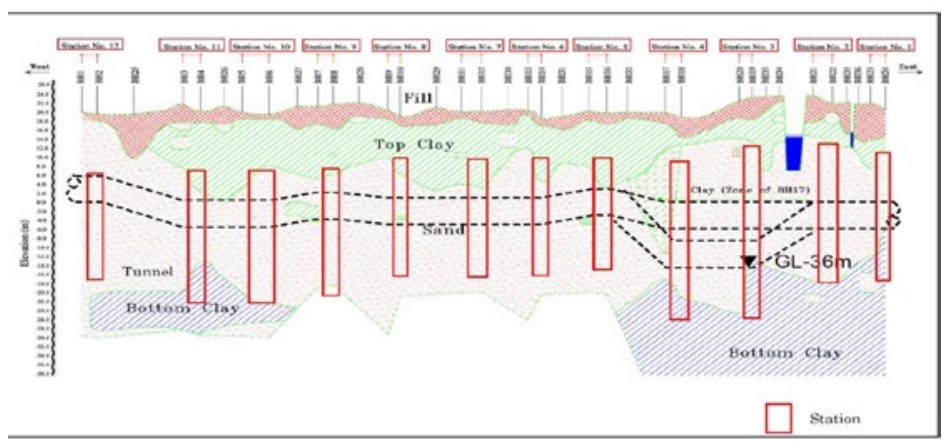

Fig. 3.

Generalized Geological Profile with Station and Rail Levels

Source: JICA Project document (2011) 
Table 1

Soil Parameters Sand Layers

\begin{tabular}{|l|l|l|l|}
\hline $\begin{array}{l}\text { Soill layers } \\
\text { Parameters }\end{array}$ & $\begin{array}{l}\text { Dense } \\
\text { Sand }\end{array}$ & $\begin{array}{l}\text { Very Dense } \\
\text { Sand }\end{array}$ & $\begin{array}{l}\text { Silty- } \\
\text { Sand }\end{array}$ \\
\hline $\begin{array}{l}\text { Saturated unit weight, } \gamma_{\text {sat }} \\
\left(\mathrm{KN} / \mathrm{m}^{3}\right)\end{array}$ & 19.00 & 20.00 & 20.00 \\
\hline Angle of internal friction $\varnothing$ & $36^{\circ}$ & $38^{\circ}$ & $38^{\circ}$ \\
\hline Young's modulus, $\mathrm{( \textrm {MPa } )}$ & 75 & 100 & 100 \\
\hline Poisson ratio $(\mu)$ & 0.29 & 0.28 & 0.28 \\
\hline
\end{tabular}

\section{Table 3}

Material Properties of Concrete Segment

\begin{tabular}{|l|l|l|}
\hline Material Properties & Concrete & Reinforcement \\
\hline Design Standard Strength $(\mathrm{MPa})$ & $F c u=50$ & $f_{y}=360$ \\
\hline Modulus of elasticity, $E_{C}(\mathrm{MPa})$ & 31500 & $2^{*} 105$ \\
\hline
\end{tabular}

Source: JICA Preparatory study (2012)

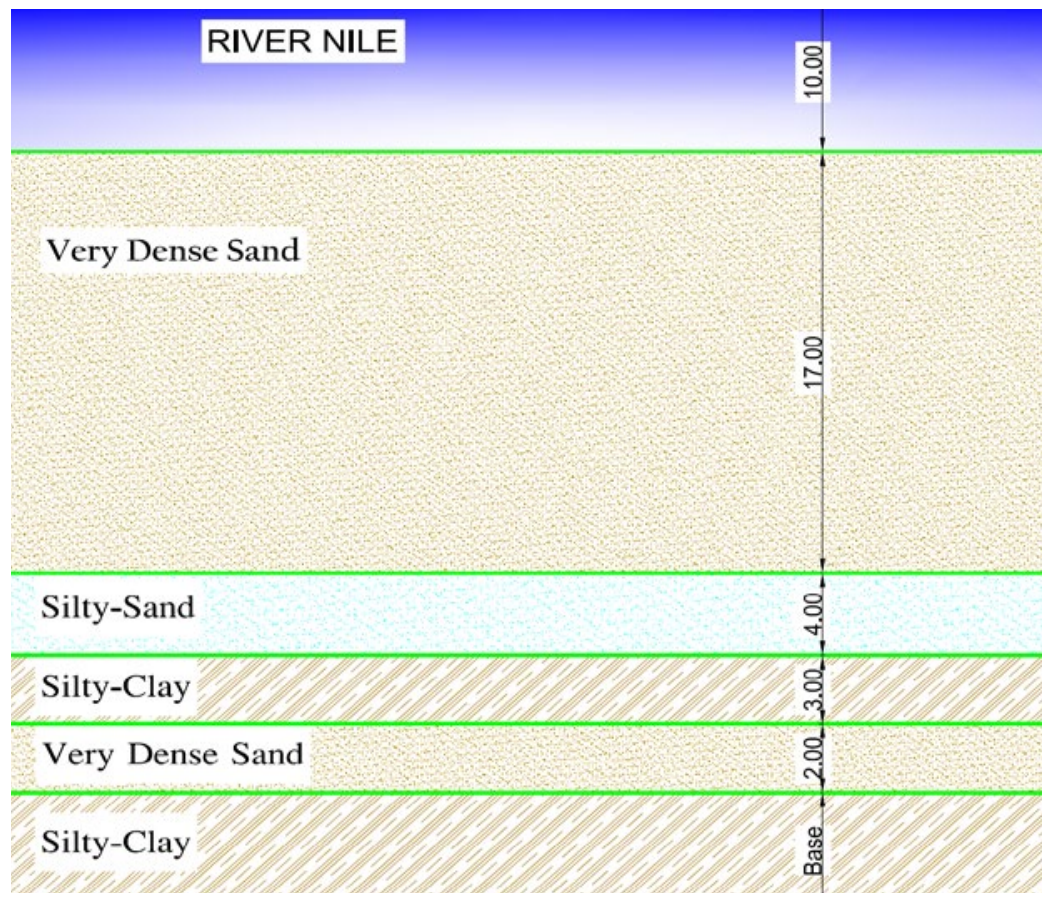

Fig. 4.

Geological Cross Section Profile of Cairo Metro Line 4 in the Study Area

Source: Ardaman-ACE (2009) 


\section{Problem Statement}

The tunneling section of line No. 4 (phase No. 1) will be constructed by Tunneling Boring Machines (TBM). The arrangement of TBMs and positions of starting diggings are illustrated in Fig.5. The contractor proposed a tunneling system that is twin tunnels with single track. In this study, the analysis of this system with another system proposed by the authors which is a single tunnel with two tracks, as shown in Fig. 6, will be presented. The proposed cross section by the contractor for twin tunnels under the River Nile shows that the outside diameter is $6.40 \mathrm{~m}$ and lining segment thickness $0.30 \mathrm{~m}$. Also, cross section of single tunnels under the River Nile show that the outside diameter of the tunnel is $9.10 \mathrm{~m}$ and lining segment thickness is $0.50 \mathrm{~m}$. Also, tunnels separation distances and dimensions are shown in Fig. 7.

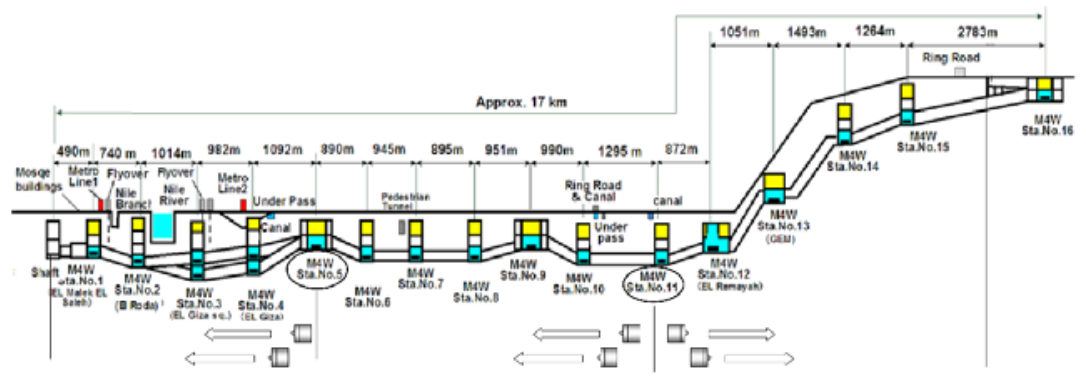

Fig. 5.

Arrangement of TBMs and Positions of Starting Diggings

Source: JICA Project document (2011)

\section{Numerical Analysis Procedure}

In this study, Finite Element Analysis was conducted using the Finite Element (FE) programs, Ansys, Civil FEM, Plaxis and Rocscience Phase. In Plaxis and Rocscience Phase programs, a 2-D plane strains elements were used for soil modeling and 2-D beam elements for tunnel lining modeling. To simulate the soil behavior, a 3-node triangular element and 15-node triangular element was used in Rocscience Phase program and, Plaxis program, respectively. In Ansys program, element type Plane 42, which is set by the model of plane strains and calculated by Drucker-Prager criteria, was used to simulate of the soil, while tunnel lining was simulated by the element type Plane 82 . Regarding the boundary conditions, the model was free at the top side and totally hinged "constrained" at the bottom, right hand and left hand side edges.

\subsection{D Model Dimensions}

All the appropriate dimensions of the base boundary were evaluated; then, the bottom boundary was fixed, and the minimum dimensions of the width of vertical boundaries were considered. The bottom boundary and model width $W$ can be obtained using the following Eqs. (1-2) (Moller, 2006):

$h=(1.5-2.5)^{*} D$

$W=2 D^{*}(1+H / D)$ 


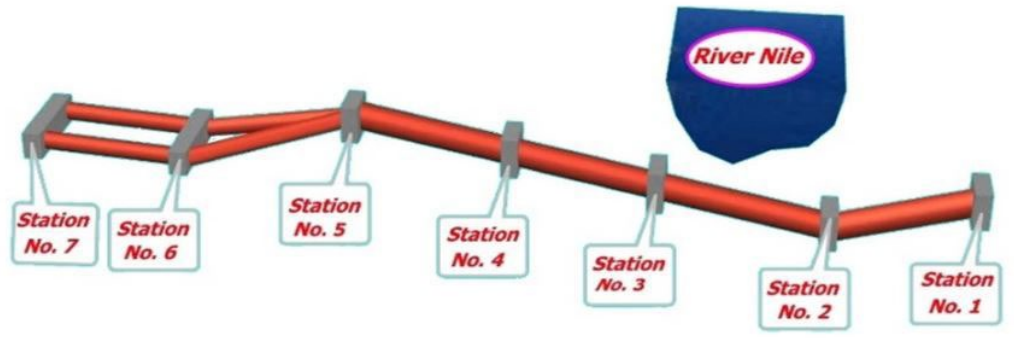

(a) Single system

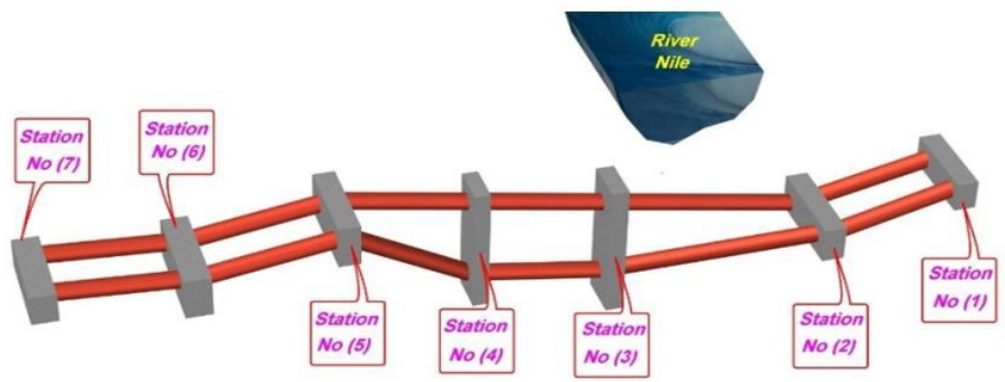

(b) Twin system

Fig. 6.

Proposed Single and Twin Tunnel System from Station No. 1 to Station No. 5

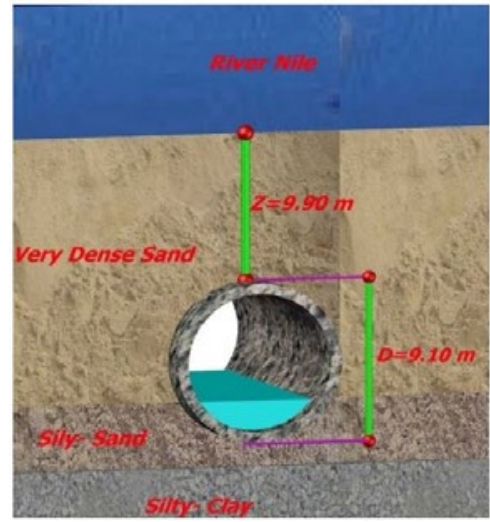

(a) Single system

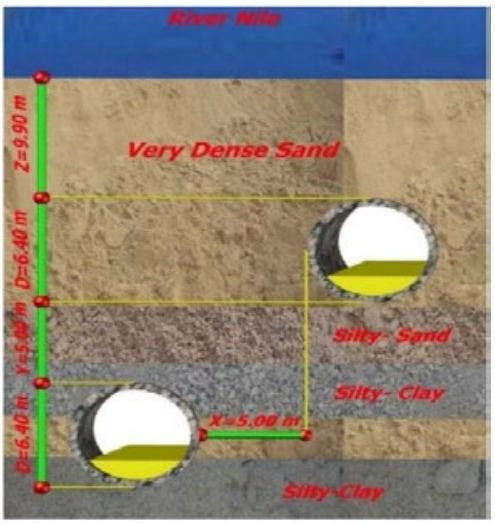

(b) Twin system

\section{Fig. 7.}

Tunnels Separation Distances and Dimensions 
It is considered in this study that $D=9.10$ $\mathrm{m}$; thus it yields a minimum dimension of the model $h=23 \mathrm{~m}$ and $H=42 \mathrm{~m}$. From previous equation $W$ is taken equal to $100 \mathrm{~m}$ as shown in Fig. 8. To find the best dimensional model, it was assumed that the minimum model width $W=100 \mathrm{~m}$. The model height $(H)$ was changed incrementally form $30 \mathrm{~m}$ to $75 \mathrm{~m}$ and it was found that the best model height $(H)$ should be $55 \mathrm{~m}$ (Fig. 9). The $55 \mathrm{~m}$ height was the best because it gave the ideal surface settlement and stresses induced at the tunnel liner. Also, if the height is taken more than $55 \mathrm{~m}$, no change occurs in both the settlement and the stresses. Also to determine the best width $(W)$, it was changed from 60 to $150 \mathrm{~m}$ while the height was kept constant at $55 \mathrm{~m}$. It was found that best width $(W)$ for the model is $120 \mathrm{~m}$ (Fig. 10). Surface settlement profile of single tunnels in case of best dimension model $\left(120^{*} 55\right)$ and surface settlement profile of twin tunnels are shown in Fig. 11 and Fig. 12, respectively.

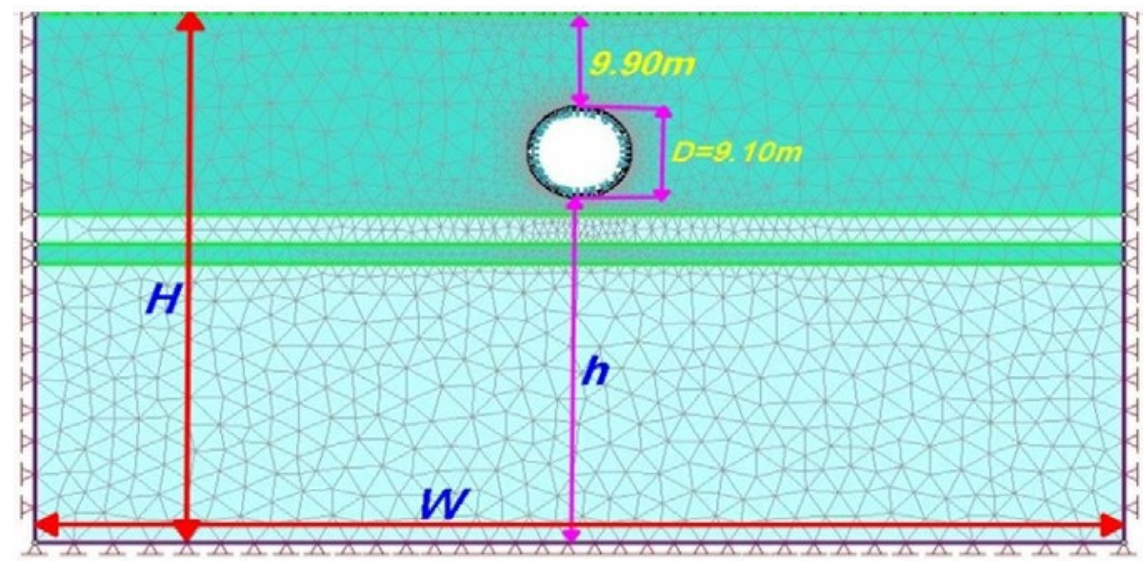

Fig. 8.

2-D Finite Element Model (Rockscience Phase Program)

\subsection{Bending Moment and Displacements}

It is so important for the designer to know the internal forces and displacements in order to design the tunnel. The following results show bending moments and settlement of single and twin tunnels. For single tunnel, the vertical displacements and bending moment diagrams are shown in Fig. 13 and Fig. 14, respectively. Moreover, Fig. 15 and Fig._16 show the bending moment and displacements of the bottom and top tunnels (twin tunnels).
Comparing the vertical displacement of the top and bottom fibers in cases of single and twin tunnels it can be noticed that vertical displacement of the top fiber is greater than that of the bottom fiber. This result explains the increase in bending moment at bottom fiber due to the high value of the bottom soil reaction. It is also noticed that, for twin tunnel, the values of stresses at the tunnel lining of the bottom tunnel is nearly double the values for corresponding points at single tunnel. It is clear from the results which are shown in Fig. 17 that in case of construction 
of top tunnel before the bottom tunnel, the bending moment will be increased for top tunnel and when constructed bottom tunnel before top tunnel. Bending moment in top tunnel will be decreased. But there is no difference in bending moment of the bottom tunnel before or after construction of top tunnel. Fig. 17 also shows bending moment of bottom tunnel after and before construction of top tunnel.

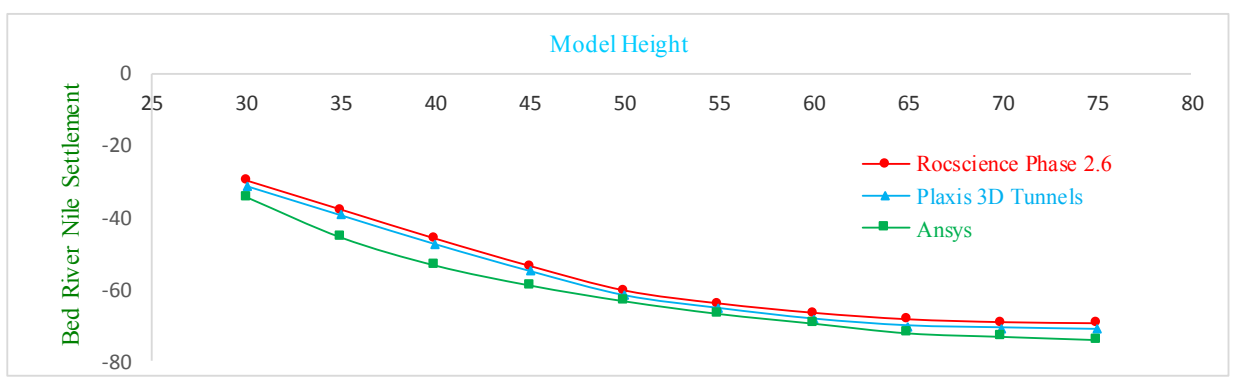

Fig. 9.

Optimum Model Height $H=55 \mathrm{~m}$

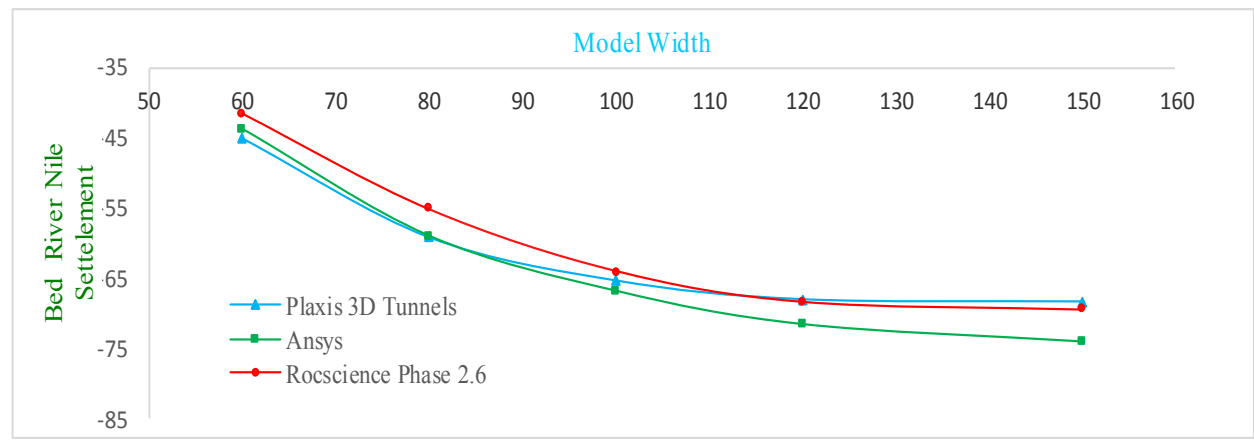

Fig. 10.

Optimum Model Width $W=120 \mathrm{~m}$

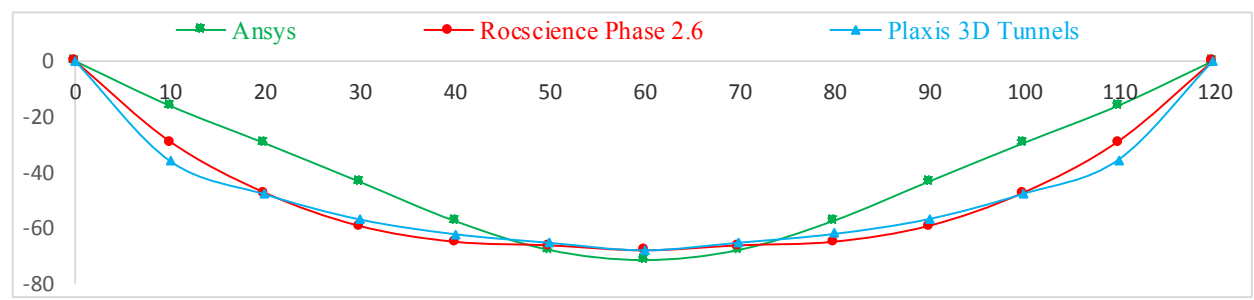

Fig. 11.

Bed River Nile Settlement Profile for Single Tunnel 


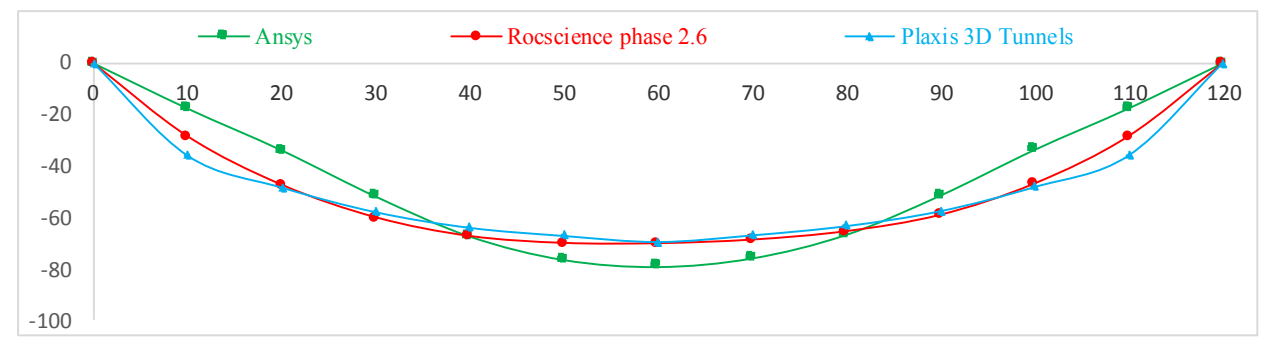

Fig. 12.

Bed River Nile Settlement Profile for Twin Tunnel

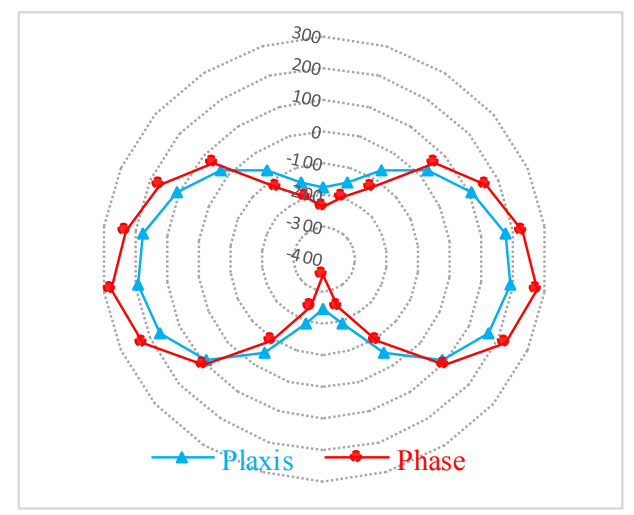

Fig. 13.

Vertical Displacement of Single Tunnel

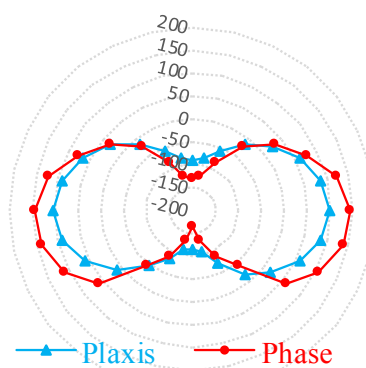

Fig. 15-1.

Bending Moment of Top Tunnel

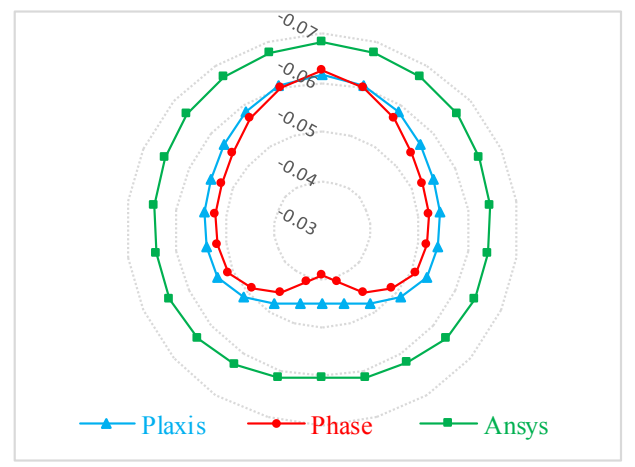

Fig. 14.

Bending Moment of Single Tunnel

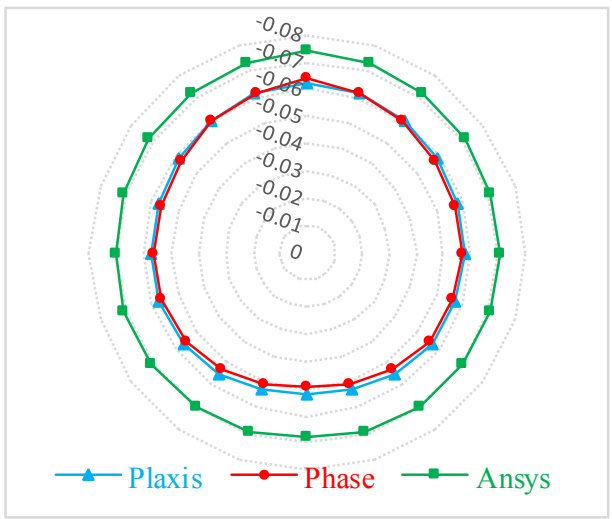

Fig. 16-1.

Vertical Displacement for Top Tunnel 


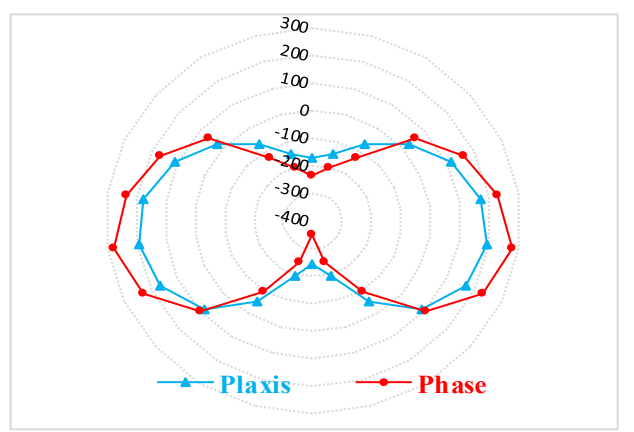

Fig. 15-2.

Bending Moment of Bottom Tunnel

\subsection{Effect of Train Loads}

The effect of train loads on settlements and stresses were evaluated for single and twin tunnels. The loads were $80 \mathrm{kN}$ on the vertical direction and $60 \mathrm{kN}$ on the lateral direction. These loads are concentrated on the tip of the rails as shown in Fig. 18. In the case of single tunnels (double tracks) the obtained results shows that the maximum settlement of the river bed changed from 71.46 to $73.52 \mathrm{~mm}$ when train passes through

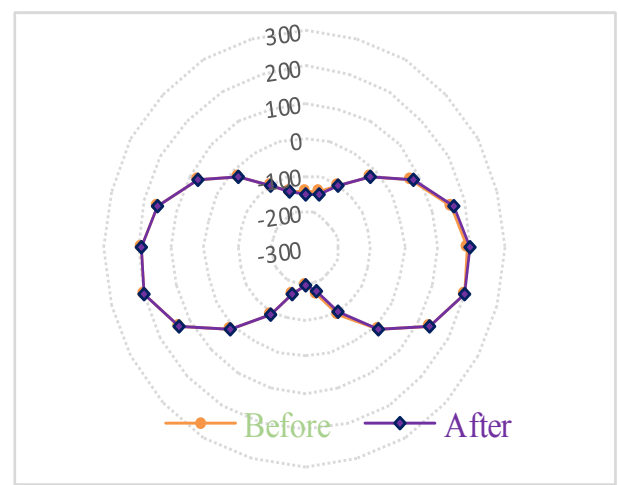

Fig. 17-1.

Bending Moment for Bottom Tunnel Before and After Construction of Top Tunnel

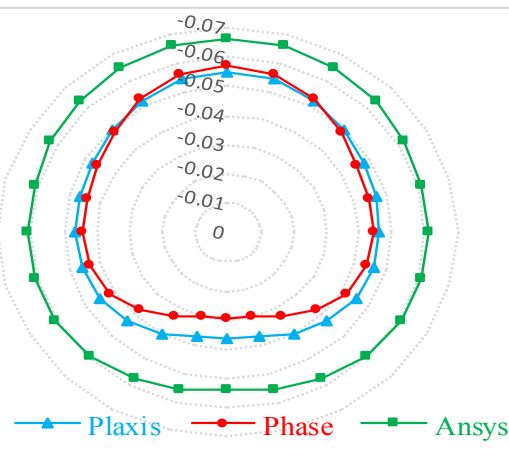

Fig. 16-2.

Vertical Displacement for Bottom Tunnel

single tunnel, whereas in the case of twin tunnel the settlement changed from 78.85 $\mathrm{mm}$ to $80.96 \mathrm{~mm}$ when train passes through twin tunnel. These results, shown in Fig. 19, indicate that the train loads slightly increased the surface settlements.

Computed stresses in lining before and after train passing through single and twin tunnels show that stresses slightly decreased when the train passes through both systems as shown in Fig. 20 and Fig. 21, respectively.

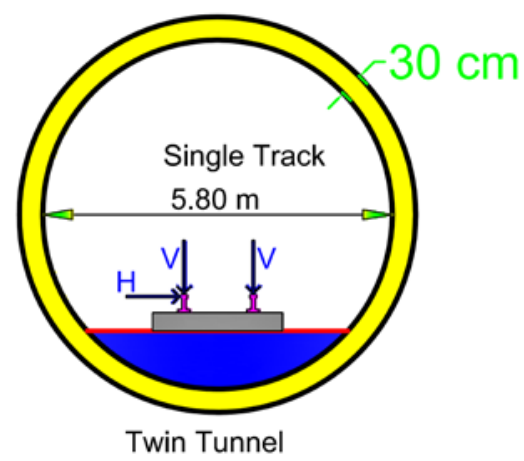

Fig. 18-1.

Cross Section for Twin Tunnels 


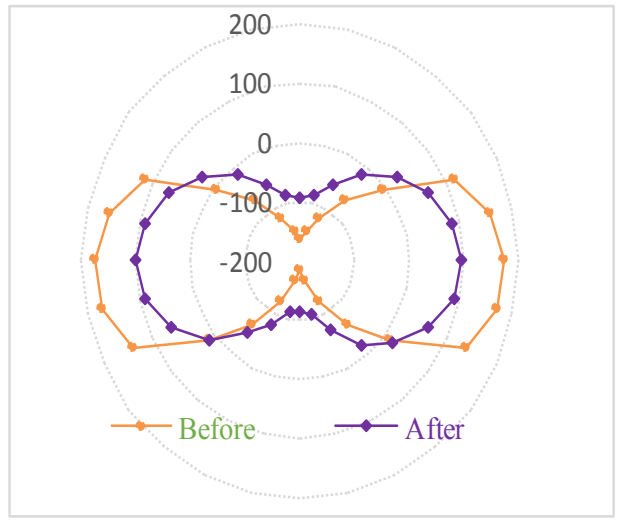

Fig. 17-2.

Bending Moment for Top Tunnel Before and After Construction of Bottom Tunnel

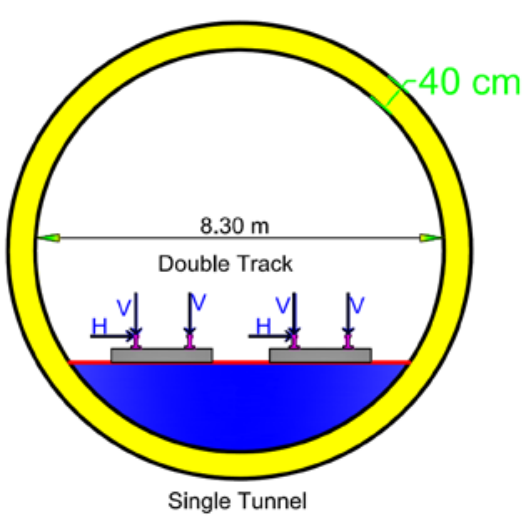

Fig. 18-2.

Cross Section for Single Tunnel

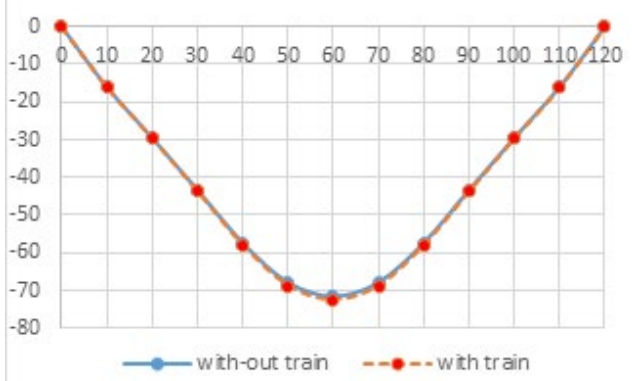

Fig. 19-1.

Effect of Train Loads on Surface Settlement for Single Tunnel

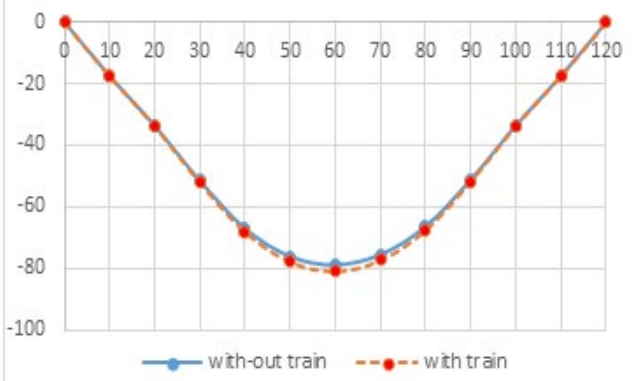

Fig. 19-2.

Effect of Train Loads on Surface Settlement for Twin Tunnels

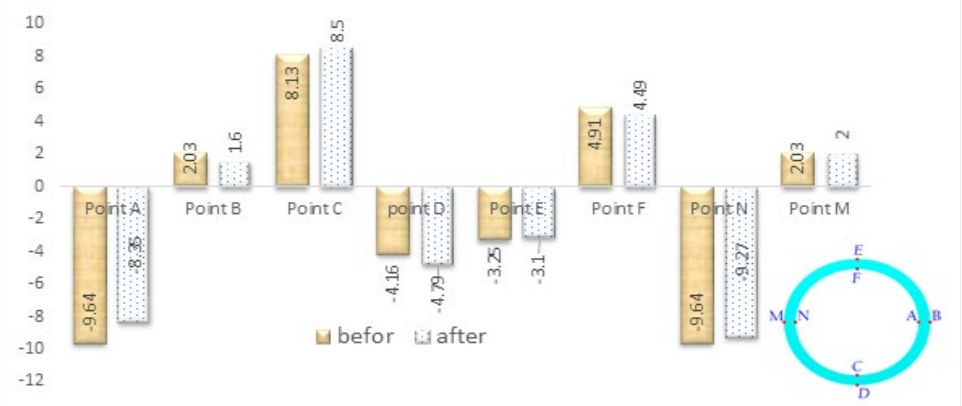

Fig. 20.

Computed Stresses in Lining Before and After Train Passing Through Single Tunnel 


\subsection{Horizontal Displacements}

From previous experiences, it is concluded that construction of tunnels causes movement of surrounding soil horizontally, as shown in Fig. 22. In urban areas, horizontal ground movement causes damage of the buildings near the tunnels. However, when tunnel passes under River Nile, horizontal ground movement causes erosion of bed level of Nile. It is clear from Fig. 22 that the direction of movement of the upper soil is in the direction of the tunnel, but for bottom soil in a direction out of tunnels. The horizontal movement profile of the bed River Nile for the single is shown in Fig. 23 and for twin tunnels is shown in Fig. 24. It is also obtained that a slight difference in horizontal movement at single and twin tunnel systems.

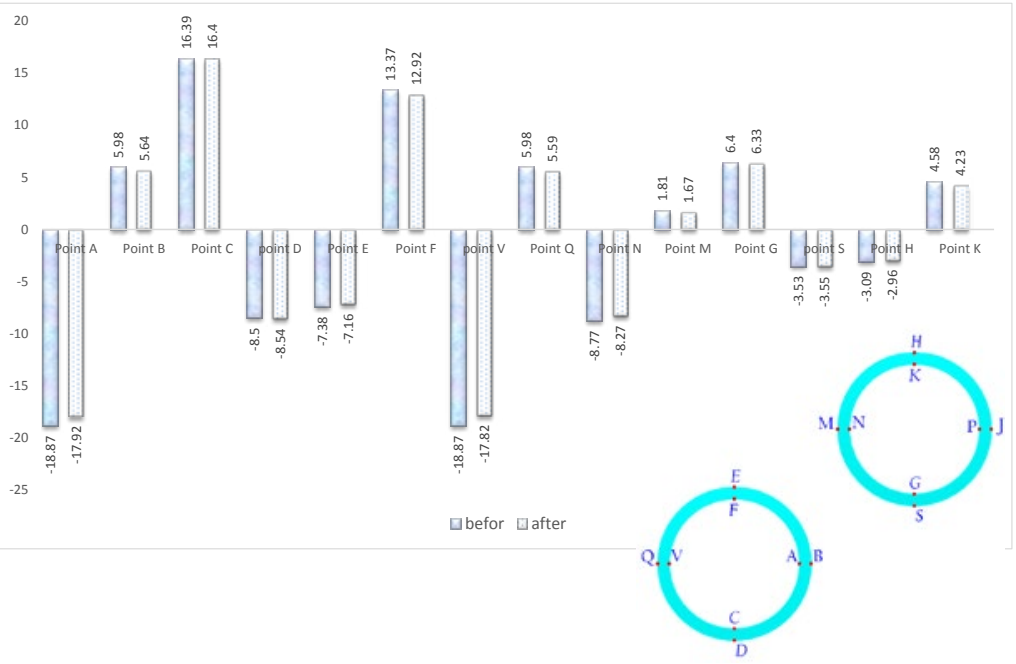

Fig. 21.

Computed Stresses in Lining Before and After Train Passing Through Twin Tunnel

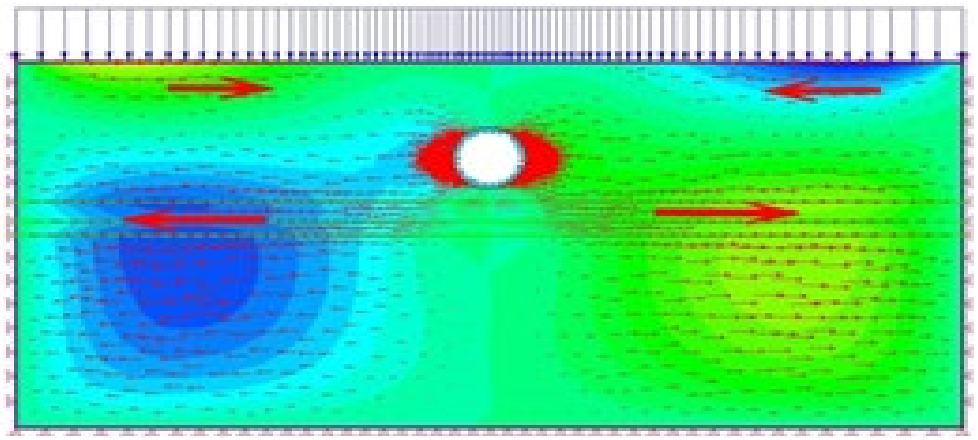

Fig. 22.

Horizontal Movement of Soils Surrounding of the Tunnel 


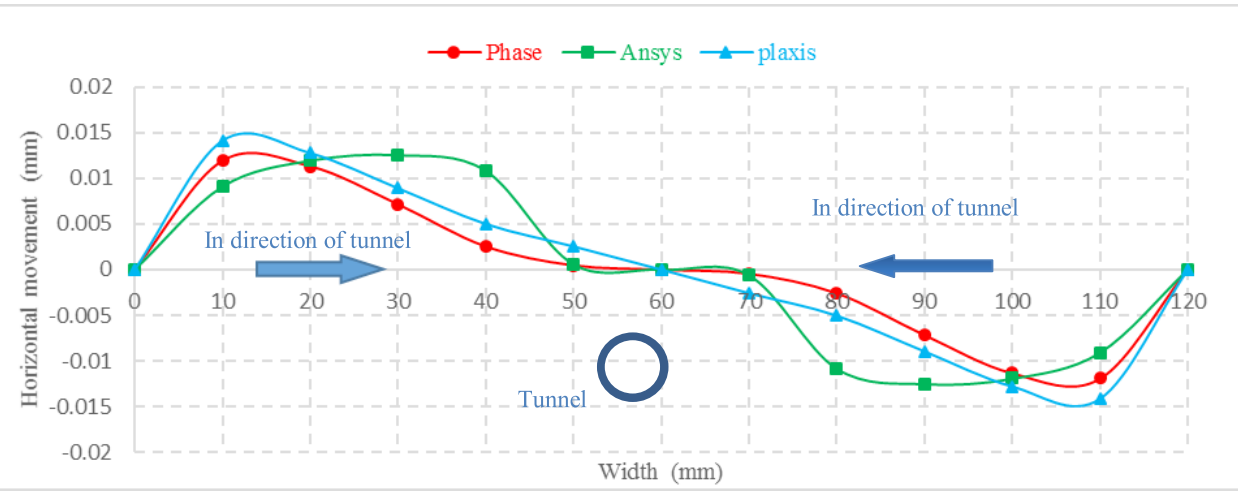

Fig. 23.

Horizontal Movement Profile of River Nile Bed Level at Case of Single Tunnel

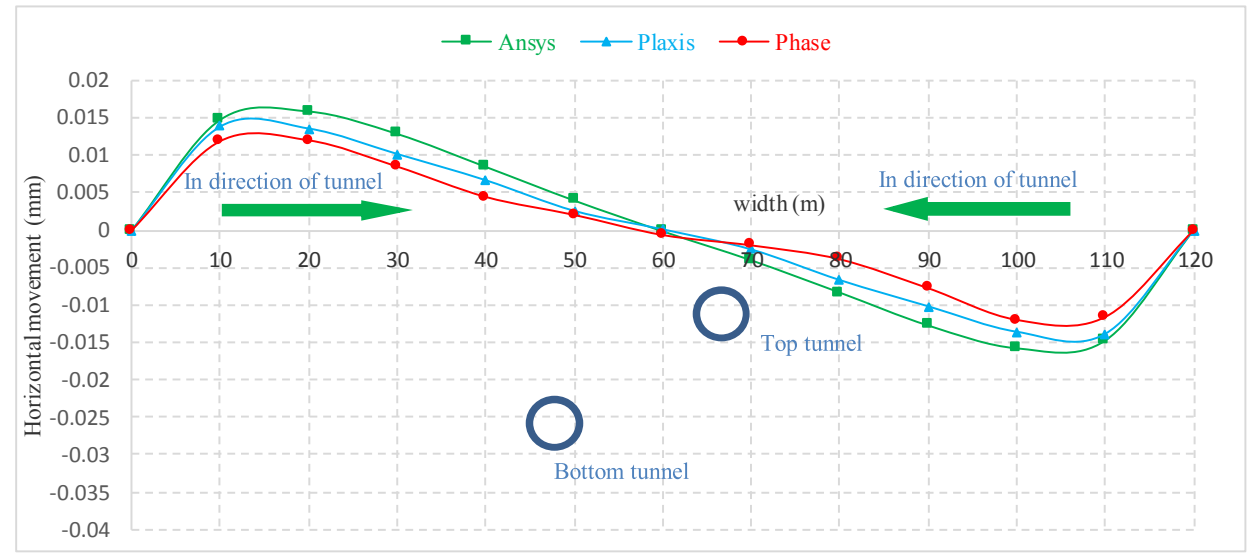

Fig. 24.

Horizontal Movement Profile of River Nile Bed Level at Case of Twin Tunnels

\section{Conclusion}

Accurate reviewing the results we concluded that:

1. Settlements and bending moments, obtained by Plaxis, Rocscience Phase were very similar. Also, results of stress analysis, obtained by Plaxis and Ansys programs, are mostly convergent. So as to, it is recommended that the Plaxis program is more reliable program for tunnel projects compared to the other used programs (Rocscience Phase and Ansys).

2. All the programs yielded the same dimensions for the optimal model of the tunnel.

3. Increasing of maximum vertical surface displacement of twin tunnel comparing with a single tunnel by $2 \%$ (small difference), and also a small difference between horizontal displacements for twin and single tunnel. 
4. A higher stress in the lining of the lower tunnel of thickness $0.30 \mathrm{~m}$ (case of twin tunnel) is obtained compared with the stress in single tunnel lining of thickness $0.40 \mathrm{~m}$, it was found, stresses in bottom tunnel (twin tunnel system) increased by $100 \%$ about stresses in a single tunnel.

5. When trains pass through the tunnel, stresses decrease about $10 \%$ for single tunnel and about 5\% for twin tunnels.

6. In case of the twin tunnel, construction of the bottom tunnel before the top tunnel is preferable to decrease the stresses in the top tunnel lining.

7. Effect of train loads on the maximum surface settlement and stresses is not significant compared with the dead loads effect.

8. The single tunnel system is the optimum system.

\section{Acknowledgements}

Authors would like to acknowledge the providing of data by the members of National Authority of Tunnels in Cairo.

\section{References}

Ardaman - ACE. 2009. Geological Cross Section Profiles of Cairo Metro Line 4.

Chehade, F.H.; Shahrour, I. 2008. Numerical analysis of the interaction between twin-tunnels: Influence of the relative position and construction procedure, Tunnelling and Underground Space Technology. DOI: http://dx.doi. org/10.1016/j.tust.2007.03.004, 23(2): 210-214.
Chen, S-L.; Gui, M-W.; Yang, M-C. 2012. Applicability of the principle of superposition in estimating the ground surface settlement of twin- and quadruple-tube tunnels, Tunnelling and Underground Space Technology. DOI: http:// dx.doi.org/10.1016/j.tust.2011.10.005, 28(2012): 135-149.

Garner, C.E.; Coffman, R.A. 2012. Subway tunnel design using a ground surface settlement profiles to characterize an acceptable configuration, Tunnelling and Underground Space Technology. DOI: http://dx.doi.org/10.1016/j. tust.2012.06.013, 35(2013): 219-226.

Khalil, A. 2002. The Effect of Different Design Parameters of Suburban Curved Tracks on Wear and Lifetime of Rails, Doctoral thesis. $141 \mathrm{p}$.

Mazek, S.A. 2011. 3-D Nonlinear Numerical Analysis to study the Performance of Twin Tunnel System, Civil Engineering Department, Military Technical College, Cairo, Egypt.

Mazek, S.A.; Almannaei, H.A. 2013. Finite element model of Cairo metro tunnel-Line 3performance, Ain Shams Engineering Journal. DOI: http://dx.doi.org/10.1016/j. asej.2013.04.002, 4(4): 709-716.

Migliazza, M.; Chiorboli, M.; Giani, G.P. 2009. Comparison of analytical method, 3D finite element model with experimental subsidence measurements resulting from the extension of the Milan underground, Computers and Geotechnics. DOI: http://dx.doi.org/10.1016/j. compgeo.2008.03.005, 36(1-2): 113-124.

Moller, S.C. 2006. Tunnel induced settlements and structural forces in linings. Doctoral thesis. $174 \mathrm{p}$.

National Authority for Tunnels (NAT). 2009. ArdamanACE, Boring Holes for Line No. 4 project. 
National Authority for Tunnels (NAT). 2010, 2011, 2012. Japan International Cooperation Agency (JICA), Project Documents.

Nejati, H.R.; Ahmadi, M.; Hashemolhosseini, H.; Hayati, M. 2012. Probabilistic Analysis of Ground Surface Vibration Due to Train Movement, a Case Study on Tehran Metro Line 4, Geotechnical and Geological Engineering. DOI: http:// dx.doi.org/10.1007/s10706-012-9528-z, 30(5): 1137-1146.

Wang, C.; Su, Z. 2011. Feasibility Study on Step Method Excavation of Tunnels with Large Cross Section and Small Interval. In International Conference on Environmental Science and Engineering. DOI: http://dx.doi.org/10.1016/j. proenv.2012.01.316, 12(Part A, 2012): 550-554.

Wang, Z.; Wong, R.C.K.; Li, S.; Qiao, L. 2012. Finite element analysis of long-term surface settlement above a shallow tunnel in soft ground, Tunneling and Underground Space Technology. DOI: http://dx.doi.org/10.1016/j. tust.2012.02.010, 30(2012): 85-92. 